\title{
Relationship between Prevalence of Malaria infection and Significant Spread of Electrolyte Variation in Malaria Patients: Within and Outside Limit Analysis.
}

\author{
* James A. Ndako ${ }^{1}$, Charles E. Okolie ${ }^{1}$, Victor T. Dojumo ${ }^{2}$, Victor O. Fajobi ${ }^{2}$, \\ Jeremiah A. Akinwumi ${ }^{2}$ Akinyomade O. Owolabi ${ }^{1}$ \\ *Corresponding Authour:nda3ko.james@Imu.edu.ng Phone Numbers: 07038540403 \\ ${ }^{1}$ Department of Microbiology Landmark University Omu-Aran,-Nigeria. \\ ${ }^{2}$ Department of Medical Laboratory Services, Landmark University Medical Center, Omu-
} Aran-Nigeria

Background: Malaria is one of the most common diseased conditions across most developing countries caused by one of four species of Plasmodium. P. falciparum and P.vivax are the main agents responsible for malaria in Nigeria. Malarial infection has been shown to be associated with abnormalities in fluids, electrolytes and acid base balances. Electrolyte imbalance and mineral disturbances are majorly identified clinical symptoms in various infectious diseases including malaria. Electrolyte imbalance in malarial infection is capable of enhancing disease severity. The aim of this study was to investigate the effects of malarial infection on electrolytes parameters. Methods: Finger prick blood samples, Thick and Thin Giemsa-stained blood smears, were collected from 100 malaria-suspected individuals representing all age groups. The Giemsastained blood smears were examined microscopically. Demographic information was obtained using structured questionnaires. The electrolytes levels $\left(\mathrm{Na}, \mathrm{K}, \mathrm{Cl}^{-}\right.$and $\mathrm{HCO}_{3}$ ) in malarial patients were analyzed using standard procedures, Pearson's Correlation Coefficient correlation technique was used to investigate the relationship, and the strength of association between the variables. Results: The mean bound of patients' sodium level was observed to fall within the specified normal limits of $125 \mathrm{mmol} / \mathrm{L}$ - $145 \mathrm{mmol} / \mathrm{L}$; except for positive malaria patients belonging to the MP-(++) which will fall below the $125 \mathrm{mmol} / \mathrm{L}$ (i.e. $126.25 \mathrm{mmol} / \mathrm{L}-$ $1.77 \mathrm{mmol} / \mathrm{L}=124.48 \mathrm{mmol} / \mathrm{L})$. The spread of the sodium data taken from the patients were observed to fall within the normal limits leaving only the boxplot's lower whisker out, that is, observations falling within the first quartile, except for MP-(++) patients with observations in the first to second quartile spreading outside the normal lower limit, in contrast for the negative tested patients, the box and its whiskers were almost engulfed within the normal limits. Conclusion: In our study we found that Plasmodium falciparum altered more in electrolytes parameters than Plasmodium vivax. The biochemical markers can be used as biomarkers to confirmation of malaria. This study discovered a significant linear relationship based on the Pearson product-moment correlation between creatinine and urea, potassium and chloride, potassium and creatinine, potassium and urea. The mean sodium and chloride level of positive malaria $[\mathrm{MP}-(++)]$ patients were observed to fall outside the normal limit.

Keywords: Malaria, Electrolytes, Plasmodium falciparum, Plasmodium vivax, Pearson's Correlation Coefficient. 


\section{Introduction}

Malaria is one of the most widespread infectious diseases among humans and endemic in tropical and subtropical regions with highest prevalence in Africa and Southeast Asia, It is also one of the major public health problems in Nigeria, contributing a quarter of the malaria burden in Africa.(1). Humans are infected by five Plasmodium species which are $P$. falciparum, $P$. malariae, $P$. ovale, $P$. vivax and $P$. knowlesi. although malaria infection is mainly caused by $P$. vivax and $P$. falciparum (2). Electrolytes are defined as minerals found in blood and other body fluids. For appropriate physiological processes to take place hence, vital for the essential life processes. These are the ionized salts (minerals) found in humans' body fluids and the blood stream. for this reason it is vital to determine the optimum range mostly during infection (3). In various infections including malaria, electrolyte imbalances and mineral disturbances were identified as the most indicative clinical symptoms. Hyponatraemia, hyperkalaemia, hypocalcaemia and hypomagnesaemia usually develops as a result of infection with Plasmodium (4). The major cationic extracellular fluid is known as Sodium (Na), which aids the regulation of normal water distribution and osmotic pressure in several body fluids. $\mathrm{Na}^{+}$ion disturbance is a cause of major health problems (5). Hyponatraemia, is referred to as decline in the amount of $\mathrm{Na}$ concentration and considered as an important clinical manifestation of malaria.

Coincidentally, decreased levels of $\mathrm{Na}$ exaggerates the disease symptoms and results in severe malaria condition in most patients (6). For all body cells, tissues and organs to accurately function, Potassium $(\mathrm{K})$ is identified as a crucial electrolyte which is vital for the proper function of all body cells, tissues and organs. It further enhances the maintenance of blood $\mathrm{pH}$ and water levels in the body. A major importance of Potassium is its role in skeletal and smooth muscle contraction. Hypokalaemia, most times is a common complication of severe malaria. A noticeable treatment for acidosis in malaria is a decline in the level of Potassium (7). Calcium (Ca) on the other hand is considered an essential nutrient for human body whereby bones and teeth in the body are strengthened as a result of the presence of calcium in the body due to its relevance in maintaining health and nutrition of the body (8).

During a malaria infection, most noticeable symptom is reduction in calcium level. Clinical symptoms associated with malaria like sweating, shivering, fever, high pulse rate are most times causes of reduction in calcium levels (9). Magnesium (Mg) is an important element which is a cofactor of more than 300 enzymes. It is involved in the regulation of blood glucose, protein synthesis, neuromuscular function, blood pressure and various biochemical processes. (10). In most cases of malaria caused by P. falciparum, there is an observed decline in the levels of Magnesium due to the illness (11). Electrolyte imbalance appears because of malaria and can likely lead to a virulent onset of the disease. The present study aimed to find out the levels of $\mathrm{Na}$, $\mathrm{K}, \mathrm{Ca}$ and $\mathrm{Mg}$ in malarial patients suffering from both $P$. vivax and $P$. falciparum in our study location.

\section{Materials and Methods}

\section{Sample collection}

Study area and population: The study was conducted at the Landmark University Medical Center Omuaran -Nigeria, which is a tertiary health institution of learning. The study population 
comprised of randomly selected patients attending the outpatient department of the Medical facility.

Ethical permit and consent: All procedures complied with the declaration of Helsinki A proposal of the project was submitted to the Ethical Review Committee of the Landmark University Ethical Committee approved the protocol for this study.

Questionnaire and sample size: The sample size used in this research work was obtained from One-Hundred (100) volunteers, while those recruited were informed about the study and their consents obtained. Well-structured questionnaires were used to collect demographic data and other pertinent information.

Sample collection and processing: A total of one-Hundred (100) samples were included in this study consisting of 40 samples with peripheral blood film evidence of falciparum malaria, 30 samples of vivax malaria and 30 samples were taken from healthy persons as a control. Estimation of renal function and liver function tests were done using the standard method. ThreeFive (3-5) $\mathrm{ml}$ of blood was collected from each patient aseptically. Standard procedures were strictly adhered during the assay process. Blood samples aseptically collected were stored at 4$8^{\circ} \mathrm{C}$ until further processing. Data related to patients like age, gender and Plasmodium species responsible for malaria were also collected. Plasmodium parasite resides in the red blood cells resulting in their lysis. If the electrolyte level variation happens due to the presence of pathogen, it may be detected through the comparison of whole blood electrolyte levels in blood of patients and healthy individuals. Whole blood was used for electrolyte determination in the present study. The determination of electrolytes in whole blood was performed using wet acid digestion method followed by atomic absorption spectrophotometry.

\section{Estimation of electrolytes}

From each sample, $1 \mathrm{ml}$ of whole blood was shifted into beaker and $0.5 \mathrm{ml}$ of distilled water was added in it followed by the addition of $1 \mathrm{ml}$ of Hydrogen peroxide $\left(\mathrm{H}_{2} \mathrm{O}_{2}\right)$ and $4 \mathrm{ml}$ of Nitric acid $\left(\mathrm{HNO}_{3}\right)$ for wet acid digestion. The beaker was covered and left overnight. Next day, samples were heated on hot plate and $\mathrm{H}_{2} \mathrm{O}_{2}$ was added drop wise until solution became clear. After filtration, de-ionized water was added to make volume up to50ml and was stored in Teflon tubes (12).After wet acid digestion, the blood samples were analyzed for determination of $\mathrm{Na}, \mathrm{K}, \mathrm{Ca}$ and $\mathrm{Mg}$ through Atomic absorption spectrophotometer (AA 6600 Shimadzu). Standards were used for the standard curve formation and estimation of electrolyte levels in the samples.

Data analysis: Questionnaires which were handed out were manually rechecked for accurate entry of data. The data were analyzed using Pearson's correlation was used to measure linear relationship between two continuous random variables., Chi-square test was used to compare several Variables while the critical level for statistical significance was set at $\mathrm{p}=5 \%(0.05)$. ANOVA test was used to observe a significant difference between the four categories of malaria patients. 


\section{Result}

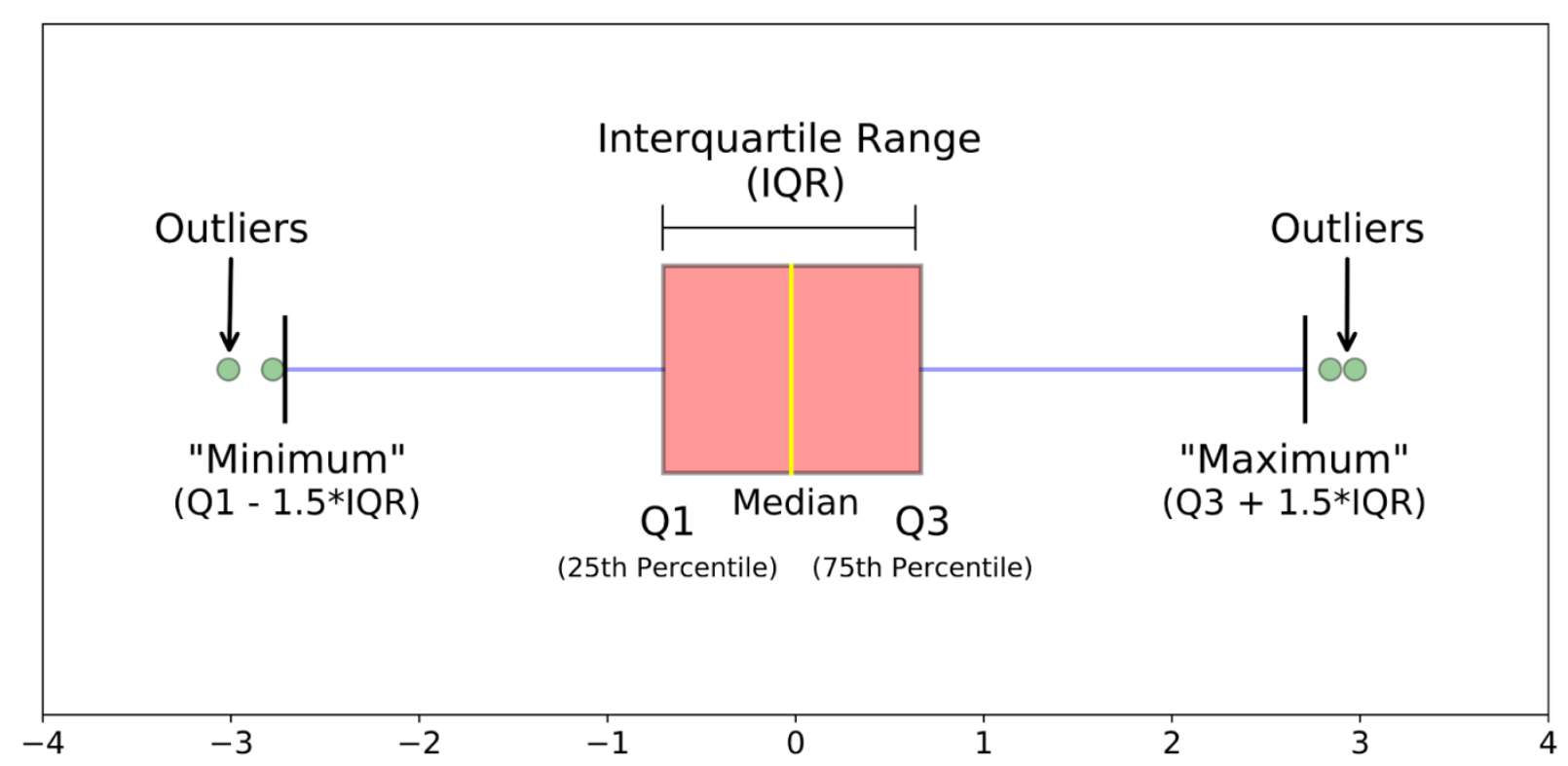

Figure 1. A Typical Description of a Boxplot

The Pearson product moment correlation usually denoted as ' $r$ ' between the electrolytes levels are presented in the upper triangle of Table 1 while the lower triangle shows the probability value for determining significance. A strong positive and significant correlation was observed between creatine and urea $(r=0.916$ and pvalue $=0.000)$ at pvalue $<0.01$. Potassium was observed to have a weak positive and significant correlation with chloride $(\mathrm{r}=0.244$ and pvalue $=0.029)$ at pvalue $<0.05$, creatine $(r=0.292$ and pvalue $=0.009)$ and urea $(r=0.327$ and pvalue $=0.003)$ at p-value $<0.01$ 
Table 1: Correlation between the Electrolyte Levels of Malaria Patients

\begin{tabular}{ccccccc}
\hline Electrolyte & $\mathbf{N a}$ & $\mathbf{K}$ & $\mathbf{C l}^{-}$ & $\mathrm{HCO}_{3-}$ & $\mathrm{C}_{4} \mathrm{H}_{9} \mathbf{N}_{3} \mathbf{O}_{2}$ & $\mathrm{CH}_{4} \mathbf{N}_{2} \mathbf{O}$ \\
\hline $\mathrm{Na}$ & 1.000 & -0.011 & 0.139 & 0.163 & -0.030 & -0.032 \\
$\mathrm{~K}$ & 0.926 & 1.000 & $0.244^{*}$ & 0.142 & $0.292^{* *}$ & $0.327^{* * *}$ \\
$\mathrm{Cl}^{-}$ & 0.219 & 0.029 & 1.000 & -0.016 & -0.014 & 0.077 \\
$\mathrm{HCO}_{3-}$ & 0.149 & 0.209 & 0.891 & 1.000 & 0.138 & 0.134 \\
$\mathrm{C}_{4} \mathrm{H}_{9} \mathrm{~N}_{3} \mathrm{O}_{2}$ & 0.792 & 0.009 & 0.900 & 0.222 & 1.000 & $0.916^{* *}$ \\
$\mathrm{CH}_{4} \mathrm{~N}_{2} \mathrm{O}$ & 0.776 & 0.003 & 0.495 & 0.237 & 0.000 & 1.000 \\
\hline
\end{tabular}

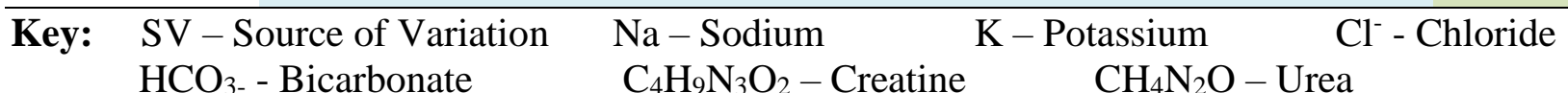

The mean bound distribution of the electrolyte levels across all the four categories of malaria patients is presented in Table 2 .

Table 2: $\quad$ Mean Statistics of Electrolyte Perturbation in Malaria Patients

\begin{tabular}{lcccccc}
\hline $\begin{array}{l}\text { Malaria } \\
\text { Status }\end{array}$ & $\mathbf{N a}$ & $\mathbf{K}$ & $\mathbf{C l}^{-}$ & $\mathbf{H C O}_{3-}$ & $\mathbf{C}_{4} \mathbf{H}_{9} \mathbf{N}_{3} \mathbf{O}_{2}$ & $\mathbf{C H}_{4} \mathbf{N}_{2} \mathbf{O}$ \\
\hline MP-nil & $132.50 \pm 4.37$ & $3.64 \pm 0.14$ & $90.85 \pm 1.14$ & $25.90 \pm 0.82$ & $198.55 \pm 75.45$ & $7.57 \pm 2.36$ \\
& & & & & & \\
MP-(+) & $129.75 \pm 1.61$ & $3.32 \pm 0.16$ & $92.05 \pm 1.38$ & $26.30 \pm 0.87$ & $95.20 \pm 18.08$ & $4.61 \pm 0.84$ \\
MP-(++) & $126.25 \pm 1.77$ & $3.20 \pm 0.13$ & $89.20 \pm 0.98$ & $24.75 \pm 0.80$ & $91.75 \pm 9.16$ & $4.34 \pm 0.86$ \\
& & & & & & \\
MP-(+++) & $130.20 \pm 1.48$ & $3.57 \pm 0.15$ & $91.95 \pm 1.22$ & $24.95 \pm 0.70$ & $112.00 \pm 22.66$ & $6.03 \pm 1.28$
\end{tabular}

Key: Mean \pm Standard Deviation

The mean bound of patients' sodium level was observed to fall within the specified normal limits of $125 \mathrm{mmol} / \mathrm{L}-145 \mathrm{mmol} / \mathrm{L}$ (Table 2), except for positive malaria patients belonging to the MP$(++)$ which will fall below the $125 \mathrm{mmol} / \mathrm{L}$ (i.e. $126.25 \mathrm{mmol} / \mathrm{L}-1.77 \mathrm{mmol} / \mathrm{L}=124.48 \mathrm{mmol} / \mathrm{L}$ ). The spread of the sodium data taken from the patients were observed to fall within the normal limits leaving only the boxplot's lower whisker out, that is, observations falling within the first quartile, except for MP-(++) patients with observations in the first to second quartile spreading outside the normal lower limit (Figure 2). 


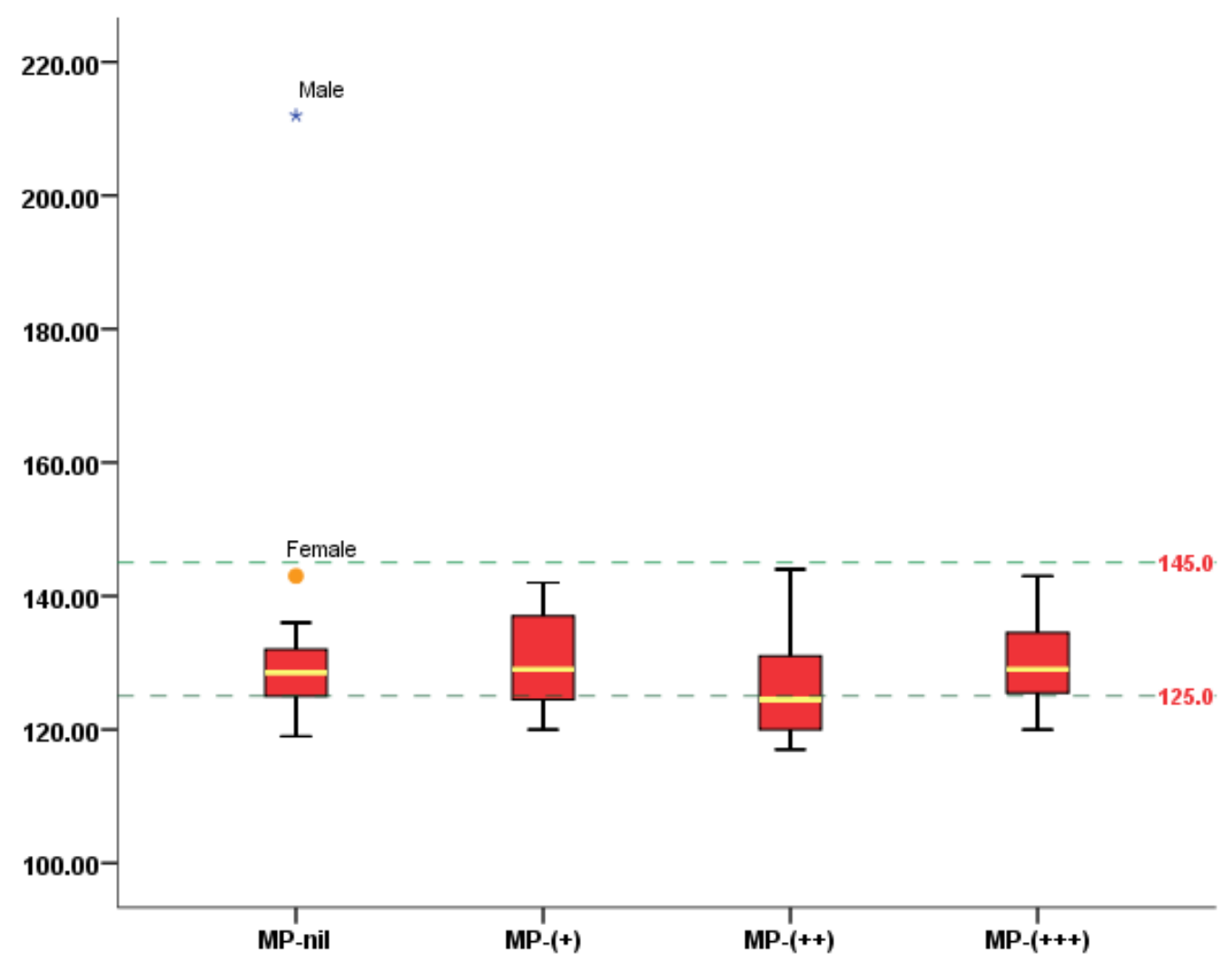

Figure 2. Spread of Sodium Level in Malaria Patients

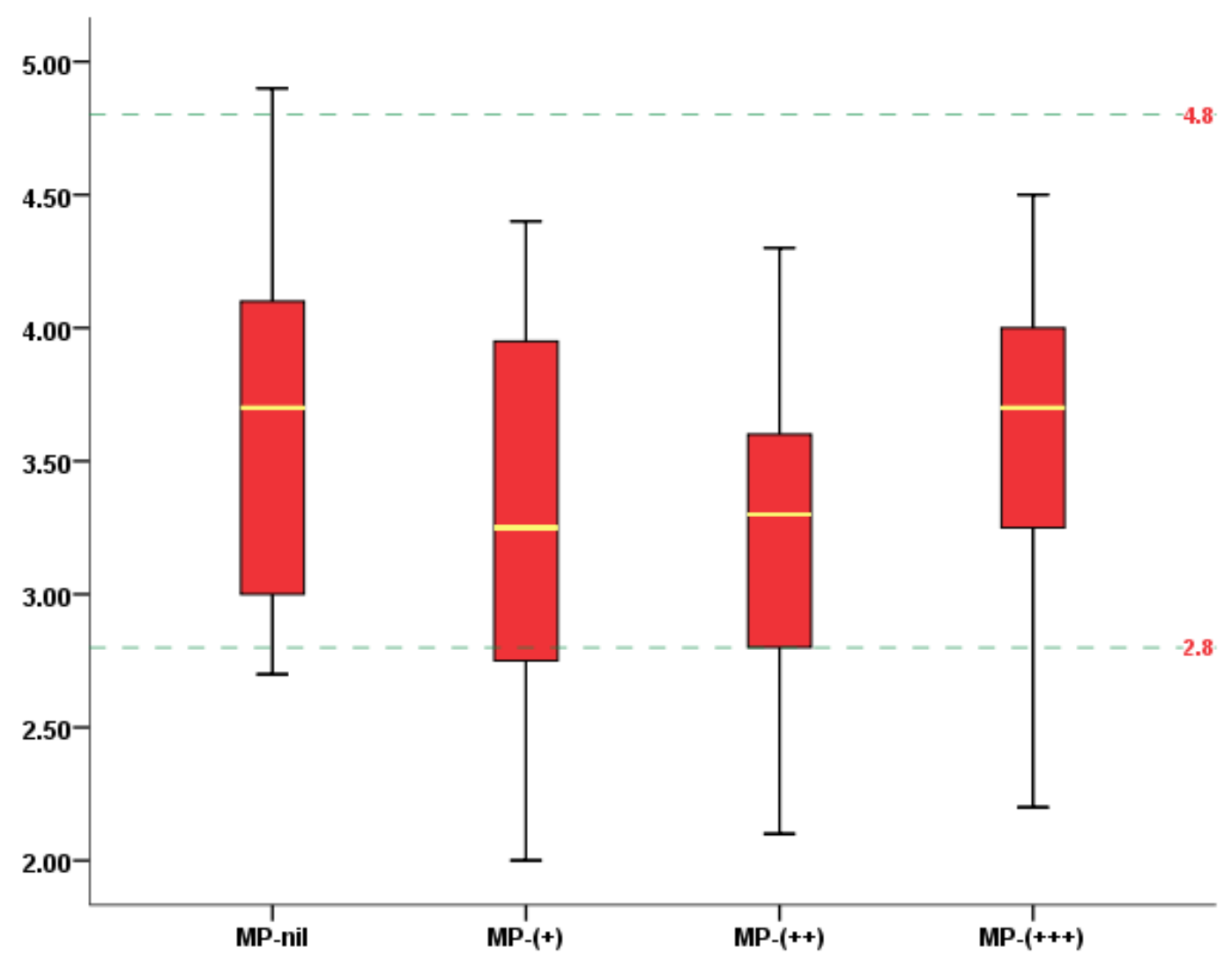




\section{Figure 3. Spread of Potassium Level in Malaria Patients}

The mean bound of patients' potassium level was observed to fall within the specified normal limits of $2.8 \mathrm{mmol} / \mathrm{L}-4.8 \mathrm{mmol} / \mathrm{L}$ (Table 2). Almost all the box spread of the potassium data taken from the patients were observed to fall within the normal limits leaving only the lower whisker out, that is, the observations in the first quartile and half of it for the MP-(+++). The case is different for the negative tested patients, the box and its whiskers were almost engulfed within the normal limits (Figure 3).

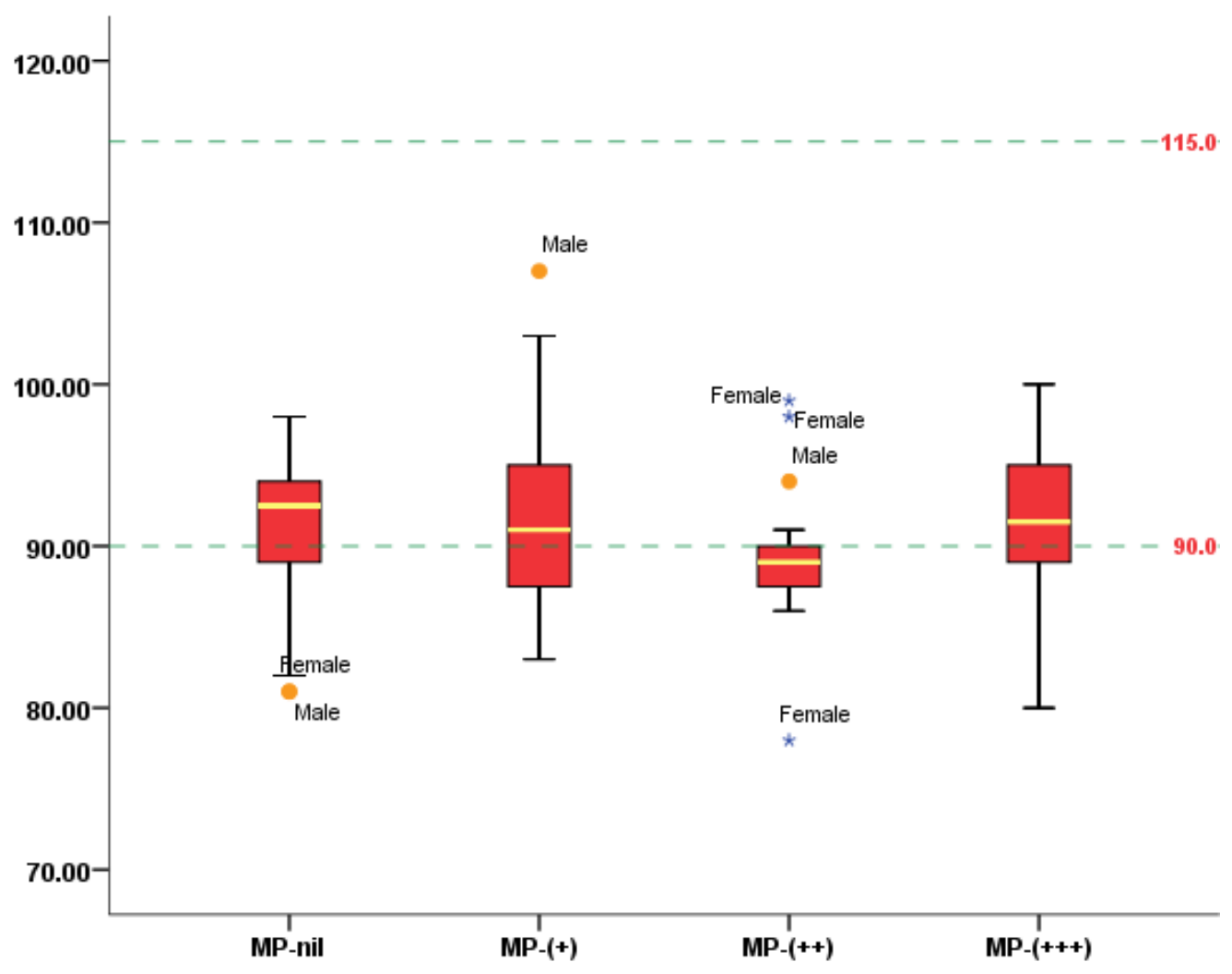

Figure 4. Spread of Chloride Level in Malaria Patients

The mean bound of the chloride level of MP-(+) and MP-(+++) malaria (positive category) patients' was observed to fall within the specified normal limits of $90 \mathrm{mmol} / \mathrm{L}-115 \mathrm{mmol} / \mathrm{L}$ (Table 2). The lower bound of the mean for negatively tested and MP-(++) malaria (positive) patients were observed to fall below the lower limit of $90 \mathrm{mmol} / \mathrm{L}$ (i.e. $90.85 \mathrm{mmol} / \mathrm{L}-$ $1.14 \mathrm{mmol} / \mathrm{L}=89.71 \mathrm{mmol} / \mathrm{L}$ and $89.20 \mathrm{mmol} / \mathrm{L}-0.98 \mathrm{mmol} / \mathrm{L}=88.22 \mathrm{mmol} / \mathrm{L}$ ) respectively. However, the box spread of the chloride data taken from the patients were observed to fall slightly outside the normal lower limit for negatively tested and positively MP-(+++) tested patients, and about half of the observations falling outside the normal lower limit for positively MP-(+) tested patients. The case is entirely different for positively MP-(++) tested patients, all the observations in the first to the third quartile spreads below the normal lower limit (Figure 4).

The mean bound of patients' carbonate level was observed to fall completely within the specified normal limits of $20 \mathrm{mmol} / \mathrm{L}-30 \mathrm{mmol} / \mathrm{L}$ (Table 2). The spread of the carbonate data taken from 
the patients were observed to fall within the normal limits except for MP-(+) patients with observations in the fourth quartile region spreading outside the normal upper limit (Figure 5).

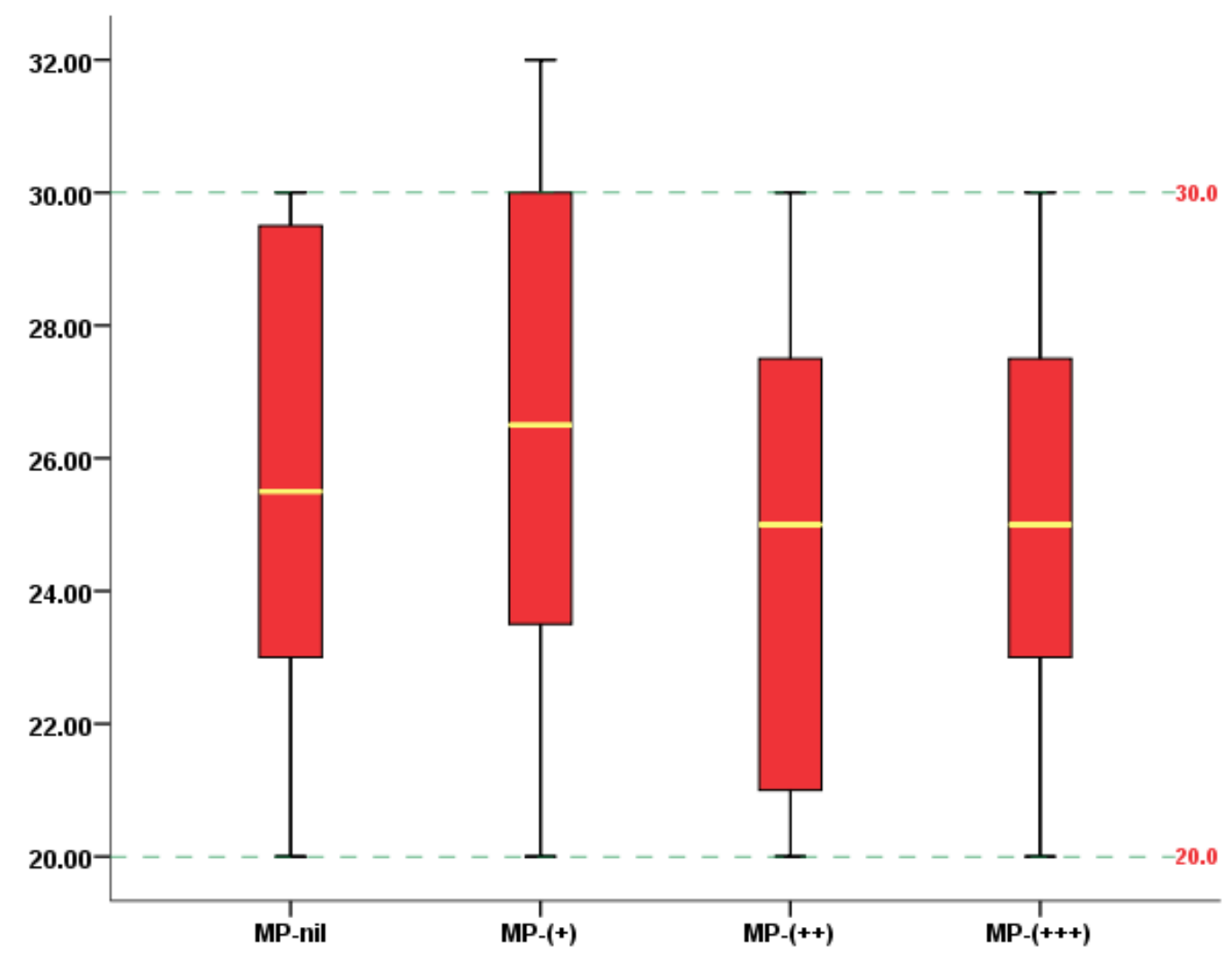

Figure 5. Spread of Bicarbonate Level in Malaria Patients 


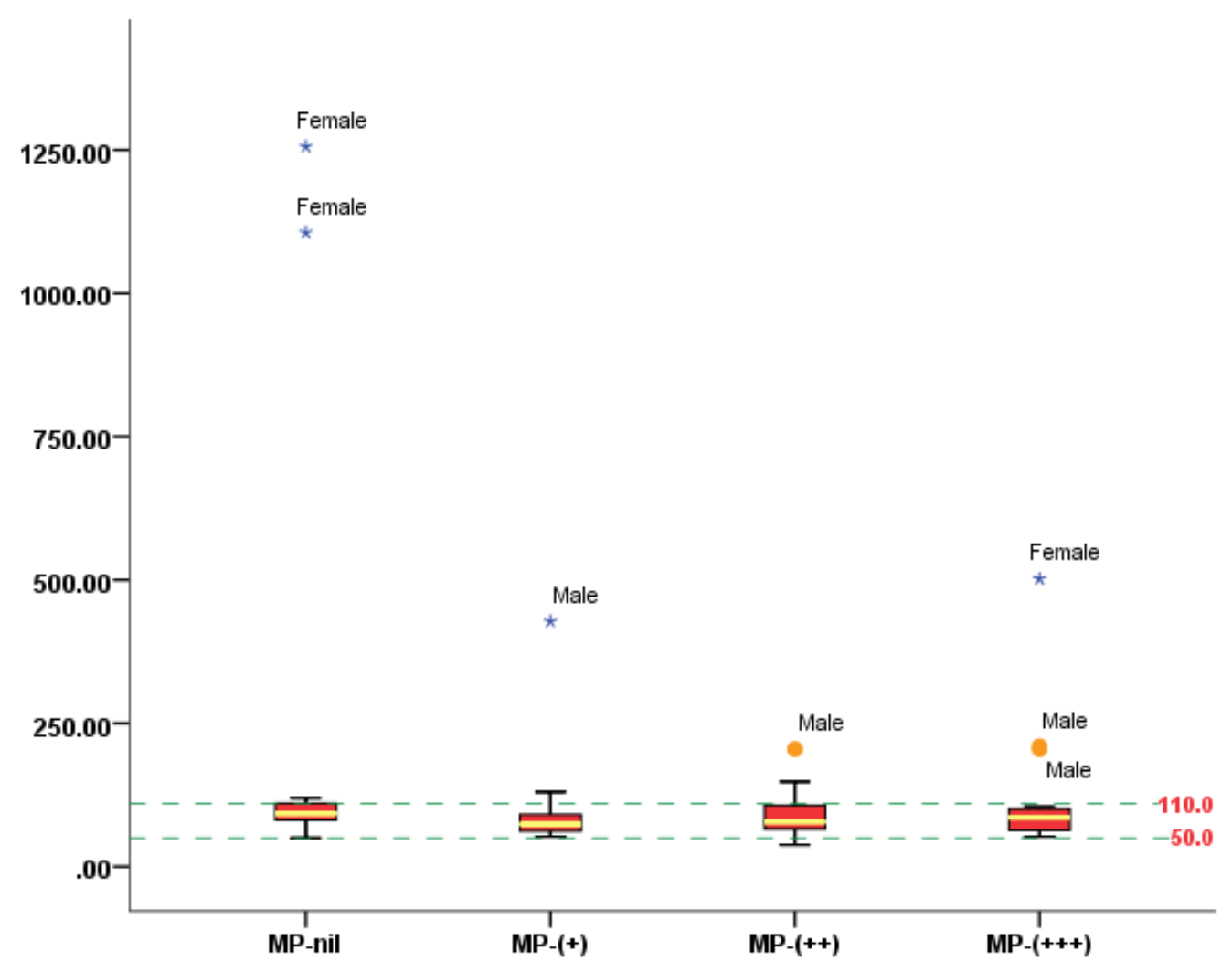

Figure 6. Spread of Creatine Level in Malaria Patients

The mean bound of patients' creatine level was observed to fall within the specified normal limits of $50 \mathrm{mmol} / \mathrm{L}-110 \mathrm{mmol} / \mathrm{L}$ for positively MP-(++) tested malaria patients and, outside the specified normal limits for negatively tested and positively MP-(+) tested malaria patients $(198.55 \mathrm{mmol} / \mathrm{L} \pm 75.45 \mathrm{mmol} / \mathrm{L}=123.10 \mathrm{mmol} / \mathrm{L}$ or $274 \mathrm{mmol} / \mathrm{L}$ and $95.20 \mathrm{mmol} / \mathrm{L} \pm$ $18.08 \mathrm{mmol} / \mathrm{L}=77.12 \mathrm{mmol} / \mathrm{L}$ or $113.38 \mathrm{mmol} / \mathrm{L}$ ) respectively while the positively MP-(+) tested malaria patients have their upper mean bound (i.e. $112.00 \mathrm{mmol} / \mathrm{L}+22.66 \mathrm{mmol} / \mathrm{L}=$ $134.66 \mathrm{mmol} / \mathrm{L}$ ) above the normal upper limit (Table 2). The high variation in the mean bound of the negatively tested patients can be attributed to the greatly distant outliers in the observations (Figure 5). The spread of the creatine data taken from the patients were observed to fall within the normal limits except for the MP-(++) patients with observations in the fourth quartile region spreading outside the normal upper limit (Figure 6). 


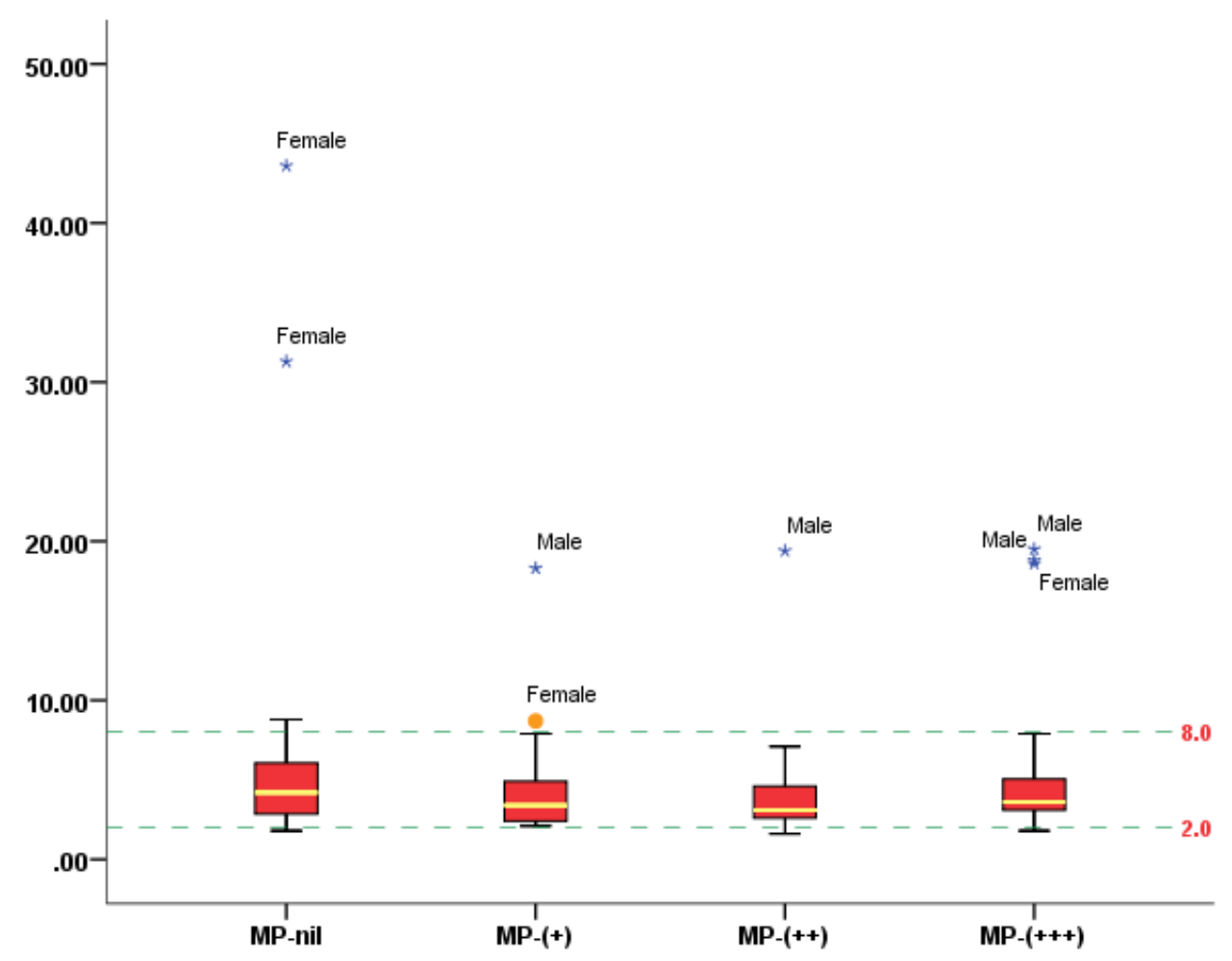

Figure 7. Spread of Urea Level in Malaria Patients

The mean bound of patients' urea level was observed to fall within the specified normal limits of $2.0 \mathrm{mmol} / \mathrm{L}-8.0 \mathrm{mmol} / \mathrm{L}$ (Table 2), except for the negatively tested malaria patients which have the upper bound of their average distribution to be above the $8.0 \mathrm{mmol} / \mathrm{L}$ (i.e. $7.57 \mathrm{mmol} / \mathrm{L}+$ $2.36 \mathrm{mmol} / \mathrm{L}=9.93 \mathrm{mmol} / \mathrm{L}$ ). The spread of the urea data taken from the patients were observed to fall within the normal limits with each of the categories having at least one outlier; two females tested MP-nil, a male and a female tested MP-(+), a male tested MP-(++) and two males and one female tested MP-(+++) (Figure 7).

Table 3: $\quad$ Analysis of Variance in the Electrolyte Level of Malaria Patients

\begin{tabular}{|c|c|c|c|c|c|c|c|}
\hline SV & df & $\mathbf{N a}$ & $\mathbf{K}$ & $\mathrm{Cl}^{-}$ & $\mathrm{HCO}_{3}$ & $\mathrm{C}_{4} \mathrm{H}_{9} \mathrm{~N}_{3} \mathrm{O}_{2}$ & $\mathrm{CH}_{4} \mathrm{~N}_{2} \mathrm{O}$ \\
\hline Between Status & 3 & 133.283 & 0.860 & 35.112 & 11.083 & 50470.950 & 44.315 \\
\hline Within Status & 76 & 135.049 & 0.413 & 28.311 & 12.720 & 33082.999 & 43.224 \\
\hline $\mathrm{F}$ & & 0.987 & 2.081 & 1.240 & 0.871 & 1.526 & 1.025 \\
\hline (P-Value) & & $(0.404)$ & $(0.110)$ & $(0.301)$ & $(0.460)$ & $(0.215)$ & $(0.386)$ \\
\hline $\begin{array}{l}\mathrm{SV}-\mathrm{Sou} \\
\mathrm{HCO}_{3-}-\mathrm{H}\end{array}$ & arbc & ion & a - Sodiu & Creatine & $\begin{array}{r}- \text { Potas } \\
\mathrm{Cl}\end{array}$ & $\begin{array}{l}\mathrm{n} \\
{ }_{2} \mathrm{O}-\text { Urea }\end{array}$ & Chloride \\
\hline
\end{tabular}


A significantly difference between the four statuses of the malaria patients was not observed from the one way analysis of variance hypothesis test conducted for sodium (F-test $=0.987$, Pvalue $=0.404)$, potassium $($ F-test $=2.081$, Pvalue $=0.110)$, chloride $($ F-test $=1.240$, Pvalue $=$ $0.301)$, carbonate $($ F-test $=0.871$, Pvalue $=0.460)$, creatine $($ F-test $=1.526$, Pvalue $=0.215)$ and urea $($ F-test $=1.025$, Pvalue $=0.386)$ at Pvalue $<0.05$ (Table 3). Although this was expected as the boxplots in Figure $2-7$ overlaps, Figure 8 further shows the similar variation possessed by the four categories of malaria patients across the six considered electrolyte measures. The distance noticed in the creatine level for the malaria patients can be attributed to the value of the outliers observed. 


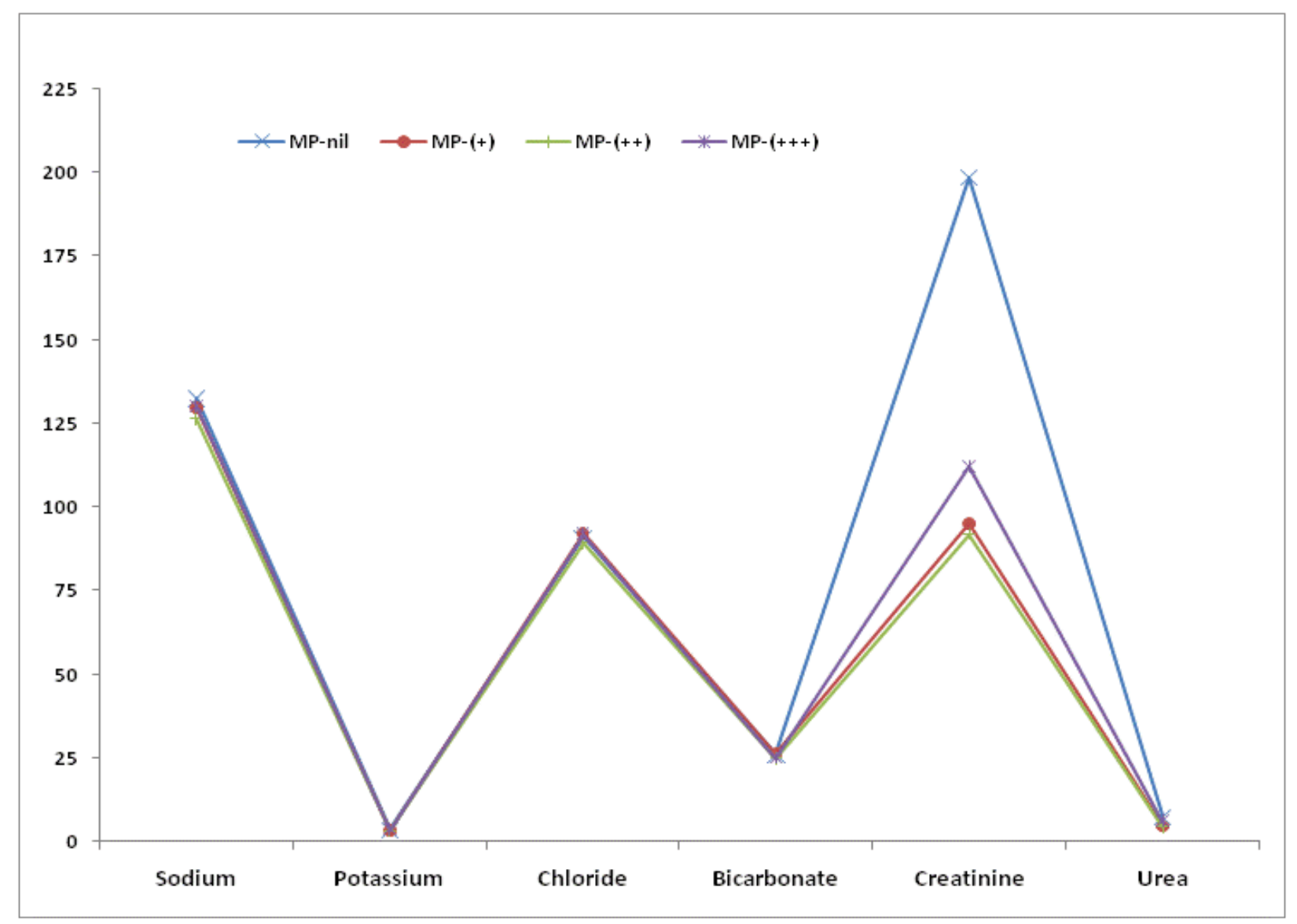

Figure 8. Marginal Means of Perturbation in Electrolyte Levels

\section{Discussion}

Malaria is a common parasitic disease of tropical and subtropical regions of the world (13).It is a highly devastating parasitic disease caused by intra-erythrocytic protozoa of genus Plasmodium. The major species responsible for deaths and that are widely spread are Plasmodium, $P$. falciparum and P. vivax (14). The human body acts as a bioelectric process while electrolytes are both the switch and the energy source for the body (15). Electrolyte imbalance has been severally observed as the commonly identified complication in severe cases of malaria. Electrolyte imbalance acts as an indicator for the level of disease virulence due to its close association with the severe $P$. falciparum and $P$. vivax malaria (16). In this study, blood samples were used for the evaluation of electrolytes in malaria patients and healthy individuals.

Findings from this study indicate that malarial infection led to the observed reduction in the levels of $\mathrm{Na}$ referred to as hyponatraemia condition. Alterations in $\mathrm{Na}$ level can result in several health conditions (17). Various literature shows reports of increased vasopressin(ADH) secretion which either appropriately or inappropriately is a key factor in the reduced level of sodium in malaria, as sodium is able to gain entry into the infected cells and cause loss of blood (18). Hyponatraemia has been identified as a common outcome of malaria (16). Ikekpeazu et al. also reported a significant lowering of sodium and Potassium levels in malaria infection(20). 
Hyponatraemia has been reported to occur frequently in patients suffering from $P$. falciparum malaria than in P.vivax malaria (16,21). Minor changes in potassium level can cause weakness, fatigue and rapid heartbeat. Therefore, its balance is very important for the normal physiology of human body (22).

The present findings showed a decline in $\mathrm{K}$ level due to Plasmodium infection,This finding is similar to the report of Ikekpeazu (20). Enhanced urinary removal of $\mathrm{K}$ and hypokalemia has been reported as common outcome of malaria infection (12). Plasmodium presence may lower the $\mathrm{K}$ levels and aggravates the complications associated with malaria disease. $P$. falciparum infected individuals were frequently observed with hypokalaemia as compared to $P$. vivax infected individuals (16).

However Maitland et al. observed no change in the level of $\mathrm{Na}$ and $\mathrm{K}$ in patients suffering from malaria as compared to healthy individuals (23).Alterations in the levels of $\mathrm{Ca}$ during malaria infection can cause several changes in the body such as muscle cramps, osteoporosis, etc. (24). It was found that Hypocalcaemia in the blood samples of malaria patients was observed compared to healthy subjects. Previous studies carried out revealed a reduction in the level of $\mathrm{Ca}$ in malaria patients (25). Trophozoites concentrate calcium in their internal compartment for metabolism (26). Our finding emphasizes a need to manage the electrolyte level of malaria patients by estimating the serum sodium and potassium ratio, while estimation of the Hyponatraemia and hypokalaemia levels could be a good marker for the severity of the disease in patients.

\section{Conclusion}

Levels of $\mathrm{Na}, \mathrm{K}, \mathrm{Ca}$ and $\mathrm{Mg}$ are influenced by the presence of both $P$. falcipaum and $P$. vivax malaria. In order to curb the spread of malaria, there is an urgent need to also manage the electrolyte derangements for overall management of malaria. It can be concluded that mineral supplementation can aid the prevention of disease severity. In this study the mean bicarbonate level of the negative [MP-nil] and positive [MP-(+++)] malaria patients were observed to fall outside the normal limit. The out of limit measurement in the mean of the negative malaria patients was traced to the presence of the outliers. Boxplots which includes the normal limits were presented for better visualization of the data spread across each category. However, an ANOVA test was used to observe a significant difference between the four categories of malaria patients.

Source of support: Authors wish to declare that there is no source funding.

Conflict of interest No conflict of interest.

Acknowledgements: Authors deeply acknowledge the Management of Landmark University Medical Center LMU-Omu-Aran for granting the approval to use the Medical Laboratory Facility. The effort of Mr. Segun L. Jegede is highly appreciated for carefully interpreting the statistical Data. 


\section{REFERENCES}

1. World Health Organization, (WHO). Global report on antimalarial drug efficacy and drug resistance: 2000-2010. World Health Organization, Geneva, Switzerland. November, (2010)

2. Aemer AK, Meera V, Humayoon SS, Adnan Y, Christopher P, Salman AM. Prevalence and distribution of human Plasmodium infection in Pakistan. Malar J. 2013;12(297).

3. Department of Health and Human Services, National Institute of Health US. Fluid and Electrolyte Balance. Medlin Plus. 2014.

4. Sitprija V. Altered fluid, electrolyte and mineral status in tropical disease, with an emphasis on malaria and leptospirosis. Nat Clin Pract Nephrol. 2008;4:91-101.

5. Andersen S, Pruden LE, Tietz N. Fundamentals of Clinical Chemistry. 2nd Ed WB Saunders Co. 1996;721-738.

6. Dondorp A, Nosten F, Stepniewska K, Day N, White N. Artesunate versus quinine for treatment of severe falciparum malaria: a randomised tria. Lancet. 2005;366(9487):717725 .

7. Maitland K, Pamba A, Fegan G, Njuguna P, Nadel S, Charles, R.J C, et al. Perturbations in Electrolyte Levels in Kenyan Children with Severe Malaria Complicated by Acidosis. Clin Infect Dis. 2005;40(1):9-16.

8. Nordin BE. Calcium and osteoporosis. Nutrition. 1997;13(7-8):664-668.

9. Golvan YJ. Elements of medical parasitology. 4th Ed Paris. 1983;275-319.

10. Rude R. Magnesium. Encycl Diet Suppl. 2010;527-537.

11. Charles EO, Ejovi O, Innocent O. Levels of iron and magnesium in serum of Plasmodium falciparum malarial infected children in Abraka, Delta State, Nigeria. J Invest Biochem. 2013;2(1):62-64.

12. Baloch S, Memon S, Gachal G, M B. Determination of trace metals abnormalities in patients with vivax malaria. Iran J Parasitol. 2011;6(2):54.

13. Conway D. Molecular epidemiology of malaria. Clin Rev. 2007;20(1):188-204.

14. Fairhurst RM, Wellems TE. Plasmodium species (Malaria). Princ Pract Infect Dis. 2009;(275).

15. Spence T. The Truth about Salt. 1999.

16. Jasani JH, Sancheti SM, Gheewala BS, Bhuva K V., Doctor VS, Vacchani AB, et al. 
Association of the electrolyte disturbances $(\mathrm{Na}+\mathrm{K}+)$ with the type and severity of the malarial parasitic infection. J Clin Diagnostic Res. 2012;6(4):678-81.

17. Fox M. Importance of Sodium. Living Strong [Internet]. 2013; Available from: http://www.livestrong.com/article/499403

18. Hanson J, Hossain, A., Charunwatthana, P., Hassan MU, Davis TM, Lam SW, Chubb SP, Maude RJ, et al. Hyponatremia in severe malaria: evidence for an appropriate antidiuretic hormone response to hypovolemia. Am J Trop Med Hyg. 2009;80(1):141-145.

19. Yoel C. Clinical symptoms and electrolytes description of children with malaria an outpatient setting in kabupatenmandailing natal. MKN. 2007;40(1).

20. Ikekpeazu E, Emeka EN, Nnenna CA, Maduka IC, Anyanwu EG. A study on malaria parasitemia :effect on the sodium and potassium levels. Biol Med. 2010;2(2):20-5.

21. Olaniyan M. The Pattern of Packed Cell Volume, Plasma Electrolytes and Glucose Levels In Patients Infected With Plasmodium falciparum. J Biol Med. 2005;6(2):87-90.

22. Peterson L. Potassium in nutrition. Handb Nutr Essent Miner. 1997;153-183.

23. Maitland K, Pamba A, Newton CR, Lowe B, Levin M.. Hypokalemia in children with severe falciparum malaria. Pediatr Crit Care Med, (2004) 5 ( 1): 81- 85..

24. Rockville M. Bone Health Health and Oste- oporosis: A Report of the Surgeon General. Dep Heal Hum Serv US. 2004;436.

25. Ayoola OO, Fawole OI, Omotade O. Calcium and phosphate levels in Nigerian children with malaria. Annu Trop Paediatr. 2005;25(4):303-306.

26. Petithory J, Lebeau G, Galeazzi G, Chauty A. Hypocalcemia in malaria.Study of correlations with other parameters. Bull SocioPathology. 1983;76(5):455-462. 